\title{
Detection of potential areas of changing climatic conditions at a regional scale until 2100 for Saxony, Germany
}

\section{Rico Kronenberg}

Dresden University of Technology, Department of Hydrosciences, 01069 Dresden, Berg Street 66, Room P 205, Saxony, Germany; Bauman Moscow State Technical University, 105005 Moscow, Baumanskaya 2-ya Street 5, Russia, e-mail: rico.kronenberg@tu-dresden.de

Johannes Franke

Saxon State Agency for Environment, Agriculture and Geology, 01326 Dresden Pillnitz, August-Böckstiegel Street 1, Saxony, Germany, e-mail: Johannes.Franke@smul.sachsen.de

\section{Christian Bernhofer}

Dresden University of Technology, Chair of Meteorology, 01737 Tharandt, Pienner Street 23, Room 108, Saxony, Germany,e-mail: christian.bernhofer@tu-dresden.de

\section{Philipp Körner}

Dresden University of Technology, Chair of Meteorology, 01737 Tharandt, Pienner Street 23, Room 105, Saxony, German,e-mail: philipp.koerner@tu-dresden.de

\begin{abstract}
Two different approaches are applied for the investigation of possible changes within the climate regime as an important component of vulnerability - on a regional scale for Saxony, Germany. Therefore data were applied from the output of the statistical climate models WETTREG2010 and WEREX-V for a projected period until 2100. In the first step, rain gauge-based precipitation regions with similar statistics have been classified. The results show that stable regions are mainly located in the Ore Mountains, while regions of higher uncertainty in terms of a climate signal exist particularly between the lowlands and mountains.

In the second step, station-based data on precipitation, temperature and climatic water balance were interpolated by the regionalisation service RaKliDa. Model runs which lay closest to the observed data for the period 1968 to 2007 were identified. Therefore, regions of similar climates were classified and compared by means of a Taylor diagram. The derived patterns of the observed data are in good agreement with formerly defined climate regions. In the final step, anomalies of 10 yearlong averages from 2021 until 2090 were calculated and then spatially classified. The classification revealed four complex regions of changing climate conditions. The derived patterns show large differences in the spatial distribution of future precipitation and climatic water balance changes. In contrast, temperature anomalies are almost independent of these patterns and nearly equally distributed.
\end{abstract}

Keywords: Multivariate statistics, cluster analysis, climate impact research, WETTREG2010, WEREX-V, RaKliDa

Submitted 13 February 2015, revised 25 June 2015, accepted 23 September 2015

\section{Introduction}

Statements about long-term changes of the climate at a regional scale are becoming of increasing importance for decision makers in politics and economics. These changes result in the challenging task of choosing appropriate action, as it affects a vast number of fields. These range from the limitation of freshwater resources (Freitas et al. 2013), potential increased dangers of crop areas due to meteo-hydrological hazards, i.e. droughts and floods, (Zhang et al. 2013) observed changes in forestry and land surface
(Renner et al. 2013), the hydraulic impact on urban drainage systems (Berggren et al. 2012), a general increasing flood risk (Wilby, Keenan 2012) and even impact on human health (Patz et al. 2005). It must be stated that the chosen examples only outline the magnitude of regional climate change and imply the need for analysis of the past and future spatial and temporal behaviour of the climate individually, and at the respective scales. For this reason, a number of regional studies investigated different aspects of observed changes of climate variables. Precipitation and temperature stand out from the pool of potential pa- 
rameters, as they are the most interesting and important in terms of limitations and extremes.

Zhang et al. (2013) investigated - with the use of copulas and Mann-Kendall tests - the probabilistic behaviours, trends and changing magnitudes in space and time of precipitation extremes in China. Their findings clearly show, for the period 1960 to 2005, a significant increase of the impact on flood and drought-affected crop areas, and they outline the necessity of respective adaptation strategies in the context of the world's most populous nation.

A decrease in observed precipitation was found by Romano and Preziosi (2013) for the Tiber region in Italy. They analysed the annual and the seasonal regime of the number of rainy days, the mean intensity and maximum daily precipitation.

These two studies already illustrate the strong invariance of precipitation in the past, which was also summarised by Reiter et al. (2011). In their study, precipitation in the Upper Danube region showed lower significance values than temperature data for the observed trends. This, according to the authors, was explained by the higher spatial and temporal variability of precipitation, and the fact that precipitation held positive as well as negative trends on seasonal and annual time series. The authors argue that due to the fact that the observed trend was not unique, a general statement for the investigated alpine region could not be made.

Furthermore, Wójcik et al. (2014) revealed in their study that the variability of precipitation challenges statistical downscaling approaches. They concluded that this was because long-term average values of gamma parameters for precipitation can be precisely reproduced by means of canonical correlation analysis, but that the short-term variability of precipitation distribution cannot.

Ashcroft et al. (2013) observed a considerable varying in the large-scale circulation features on minimum and maximum precipitation and mean sea level pressure over three sub-periods for long-term time series of different stations in Australia - this covered the period from 1871 to 2009 , and was considered natural climate variability by the authors.

In a study Nguyen et al. (2013), which had a focuson spatial patterns, changes in precipitation region boundaries for Vietnam were observed. The results were carried out for the period from 1971 to 2010 by deploying a k-means clustering on four sub-periods - each 10 years in length - for monthly values.

The observed and projected climate change and its immediate consequences demand concrete strategies and adaptation measures from local authorities (IPCC 2008). For this reason, it is of immense importance that potential regional changes in the climate regime are identified. We define those regions as climate areas with a similar longterm behaviour of precipitation, temperature and climatic water balance. While there exist many studies investigating precipitation and temperature and their properties in space and time as single factors, a lack of studies containing a more complex spatial analysis (i.e. considering more than one factor in a multivariate analysis) for the regional scale must be stated.

Addressing these issues, this paper focuses on the analysis and investigation of climate regions from a hydroclimatic perspective for the area of Saxony, Germany through the use of multivariate statistics and cluster analysis. The main issues can be summed up in the form of the following motivational questions:

1. Which element is the driving force for detecting potential areas of changing climatic conditions on a regional scale?

2. How large is the spatial heterogeneity of the projected element-spanning anomalies?

3. To what extent do regions have higher uncertainty in terms of a climate signal, with relation to precipitation, in Saxony?

This study aims to identify potential areas in Saxony affected by regional climate change, and to provide simple yet significant results for further impact related studies. The results are presented in a way that makes them accessible for climate impact research from any of the affected fields.

\section{Study region and data}

The study region is spatially limited to the federal boundaries of the Free State of Saxony. This region spans an area of $18420.15 \mathrm{~km}^{2}$. The topography within this area can be divided into lowlands, uplands and high mountain ranges up to $1200 \mathrm{~m}$ above sea level (Mannsfeld, Syrbe 2008). The climate is marked by significant differences. The annual mean temperature of the northern lowlands and central Saxon uplands lies between 8.5 and 10 degrees Celsius for the period 1991-2005, whilst the mean temperature of the mountain ridges ranges between 6 and 7.5 degree Celsius. The mean annual precipitation is distributed in a similar manner from 500 to $800 \mathrm{~mm}$ in the lowlands and 900 to $1200 \mathrm{~mm}$ in the southern mountains (SMUL 2008). Osborn et al. (2000), Drogue et al. (2006) and Daniels et al. (2013) were able to show that despite the large inter-annual variability of precipitation, topography plays an important role in the distribution of precipitation, even in northwestern Europe where gradients between precipitation and altitude are rather small. Franke et al. 
(2008) showed that a strong dependency between precipitation occurrence and altitude exists in the study region, and this leads to higher precipitation in the southern mountains. In contrast, the northwestern part of the study region is on average the warmest area, with the lowest amount of precipitation.

For the study region, different station-based data sets of mean temperature (TM), bias corrected precipitation (RR) and climatic water balance $(\mathrm{CW})$ in daily resolution are available. Observed data from 1961 to 2014 was taken from the German Weather Service's operational networks (DWD) for the analysis and validation of the recent climate, as well as projected data from 1961 to 2100 for the analysis of future climatic developments. The projected data were simulated by the statistical regional climate models WETTREG2010 (Kreienkamp et al. (2010) and WEREX-V (2011) for the period 1961 to 2100. WETTREG2010 uses the general circulation model (GCM) ECHAM5 (Deutsches Klimarechenzentrum Hamburg) as forcing, while the later WEREXV simulations are based on ECHAM5 and also on British GCMs HadCM3C and HCG2 (Met Office Hadley Centre for Climate Prediction and Research, Exeter, UK) and subsequently on regional downscaling approaches like the regional climate models REMO (MPI-Meteorologie Hamburg) and RACMO (Königl. Meteorologisches Institut der Niederlande, KMNI). The multi-model ensemble approach of WEREX-V considers emission scenarios E1 (i.e. 2-goal) and A1B. The WETTREG2010 simulations consider the A1B, A2 and B1 scenarios. These are based on Special Report on Emissions Scenarios (SRES), as were used in the 4th IPCC report (IPCC 2008). More recently Representative Concentration Pathways (RCP) have been developed, and these should replace SRES as they focus on greenhouse gas concentrations and radiative forcing instead of socioeconomic factors (IPCC 2014). According to the downscaling approaches, 10 realisations (00-99) per approach were simulated. Overall, 150 realisations were available. For this study a selection of 10 realisations (SEL) of WEREX-V was used, which resulted in 40 respective realisations investigated. The projected data refers to the same climate and precipitation stations as the observed climate data, as dominantly statistical approaches of the regional climate models were applied there.

\section{Methods}

\subsection{Regionalisation of the station-based data}

The analysis of the climate information required the regionalisation of the station-based data for further use. The regionalisation was done by the operational 'RAster-
KLIma-DAten' Service-RaKliDa, which is only available under www.rekis.org. This service was designed to provide raster-based data for climate analysis and related impact models. The produced raster data sets have a spatial resolution of $1 \mathrm{~km}$. RR; CW and TM were derived by means of a so called residual interpolation, which is based on vertical gradient approach (VG). VG is combined with an Inverse Distance Weighting (IDW) to increase the unbiasedness of the estimates. This combination means that the residual values are interpolated by IDW. A residual value is defined as the difference between observed value and the VG estimated value at the respective station. The final precipitation estimate is the sum of the estimates derived by $\mathrm{VG}$ and the respective IDW interpolated residual value.

\subsection{Detection approach for potential transition areas}

The detection of potential areas of changing climatic conditions was carried out with the use of raster-based data. The main steps of the detection approach can be seen in Fig 1a. First, the interpolation is carried out following the aforementioned approaches (cp. Section 3.1). Then low-pass filtering, z-transformation and anomaly calculation was carried out, as depicted in Fig. 1a. The procedures are carried out in the following manner: the given time series $\mathrm{X}(\mathrm{t})$ of a meteorological element is prepared for classification independently of its origin. It may be observed or modelled, point-wise or gridded data, and for each meteorological element the according annual values are calculated. Subsequently, the low pass filter follows according to Equation 1:

$$
m_{M A}^{(n)}(t)=\frac{1}{n} \sum_{i=-\frac{n-1}{2}}^{\frac{n-1}{2}} x(t+i)
$$

where:

$n=$ number of years of the filter;

$t=$ year;

$x=$ value;

with $n=11$ for 11 years orientated after the sunspot cycle (Zhao et al. 2004).

Subsequently, the time series is z-transformed to ensure comparability between different anomalies of meteorological elements, according to Equation 2:

$$
m_{M A}^{(n)^{*}}(t)=\frac{m_{M A}^{(n)}(t)-\hat{\mu}\left(m_{M A}^{(n)}\right)}{\hat{\sigma}\left(m_{M A}^{(n)}\right)}
$$

where:

$\hat{\mu}\left(m_{M A}^{(n)}\right)=$ mean value of the time series (MLE);

$\hat{\sigma}\left(m_{M A}^{(n)}\right)=$ standard deviantion of the time series (MLE). 
The anomaly of a climate element is defined in Equation 3:

$$
A N O_{S U B}=\frac{1}{d_{S U B}} \sum_{i=1}^{d_{S U B}} m_{M A, S U B}^{(n) *}(i)-\frac{1}{d_{R E F}} \sum_{i=1}^{d_{R E F}} m_{M A, R E F}^{(n)^{*}}(i)
$$

The data processing followed the cluster analysis after Ward (1963), in which all time series of all elements and all raster cells were considered. Finally a visualisation in a GIS environment for interpretation and evaluation as depicted in fig. 1a was carried out.

\subsection{Identification of areas of changing precipitation behaviour}

The detection of changing precipitation behaviour is based on data from rain gauges, as depicted in fig. $2 b$. Their monthly time series are divided into 30-year long moving sub-periods - from 1961 to 2100 - for the respective data sets. For each of the sub-periods a cluster analysis, like that introduced in Section 3.2, was deployed in s-mode. Hence, similar stations (i.e. similar in terms of similar monthly time series, which includes the amount and annual distribution of precipitation) are divided into classes of stations. These classes form areas of coherent stations.

The class number, which limits the number of coherent stations, was identified iteratively over the whole available period of all models and observations. This number was determined taking the already known number of similar climate regimes into account. When we consider the relations between precipitation and vegetation, climate variability itself influences the number of potential regions. This is why a large number should be avoided due to the fact that these small regions will most likely alternate in space with the variability of an expected change of vegetation due to changing climatic conditions.

The resulting regions after classification are, because of the station-based data, not necessarily spatially connected for one sub-period, though from sub-period to-sub period these areas are more or less constant over time. The spatial characteristics of the sub-period are visualised and summarised in a GIS environment for interpretation.

\section{Results and discussion}

\subsection{Potential areas of changing precipitation beha- viour}

A rain gauge-based classification for long time series was performed to detected potential areas of changing precipitation behavior. All available stations were assigned to one of seven classes. The results are shown in fig. 2 .
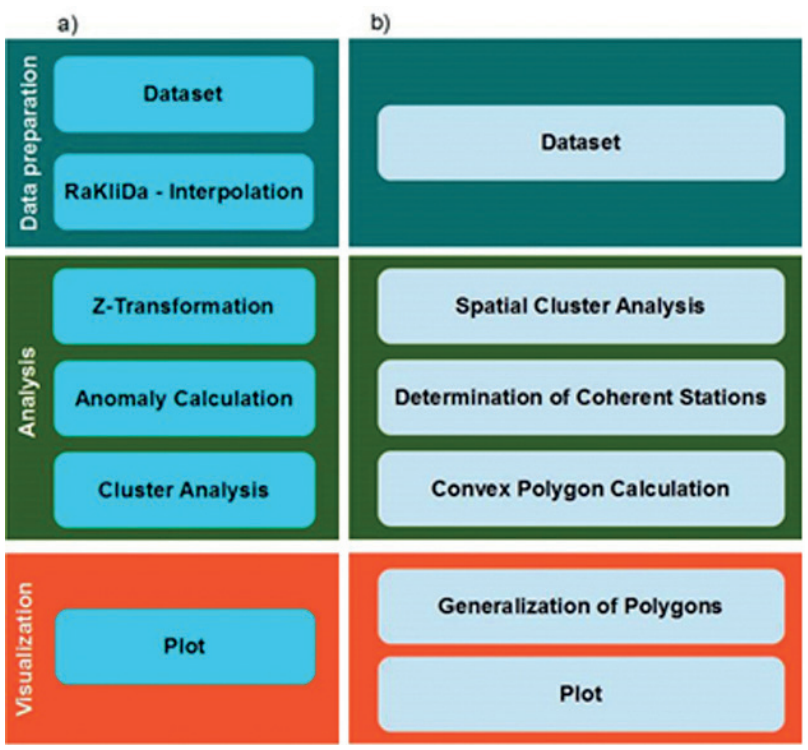

Fig. 1. Approach schemes: a) Detection approach for potential transition areas; b) Identification of areas of changing precipitation behaviour

The repeated classification, with different class numbers, resulted in more or less constant precipitation regions. These regions are constant in terms of the region's centres, but variable at their borders. Furthermore, seven regions (i.e. classes) for classification fit the already known regions of Mannsfeld and Syrbe (2008) fairly well.

The significance of the observed variability of designated homogenous precipitation regions seems to depend on the complexity of the terrain. It can be stated that for regions located in the lowlands of the domain the variability becomes more important - an increase of variance can be observed there (i.e. spatial extension of the derived regions).

In contrast, areas of high mountain ranges are less variable because climate conditions might change at their flanks due to changes in large-scale circulation systems, but their general extent and therefore orographic influence remains, while lowlands are more sensitive to land cover changes, hydroclimatic changes or other human-driven changes.

General similarities can be found between the classification of Mannsfeld and Syrbe (2008) and the classified precipitation regions. Considerable large spatial agreement was found in mountainous areas of Saxony.

The darker a red area depicted in fig. 2, the more stable it is, and the more often a respective detected precipitation region occurs. Intersections of different polygons illustrate not only the variability of the different model realisations but also of the precipitation stations themselves, which should rarely be called stationary in a climate change context. The detection method was conducted in a manner that meant only convex polygons were constructed. For 
a)

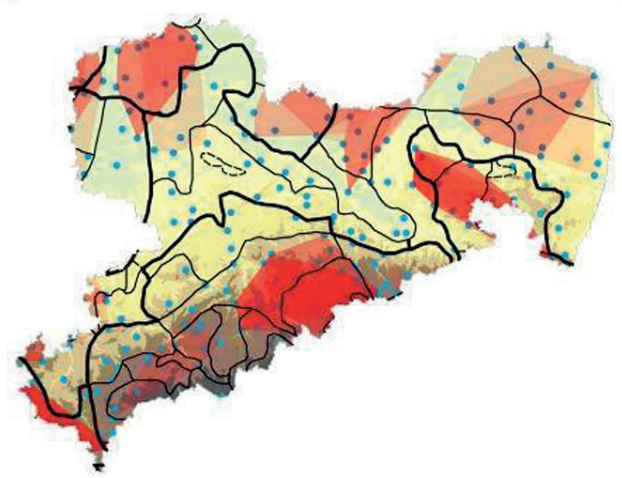

c)

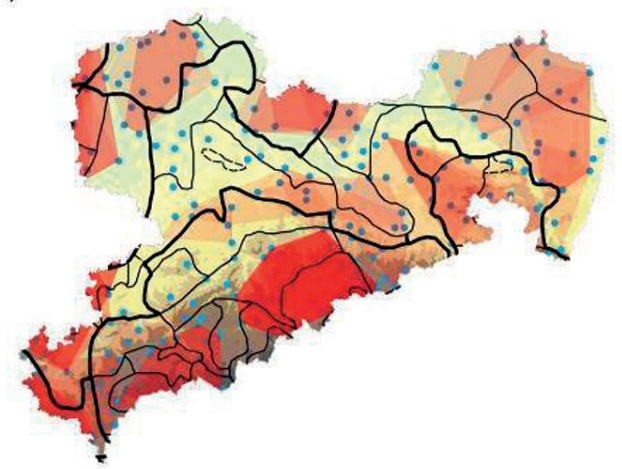

b)

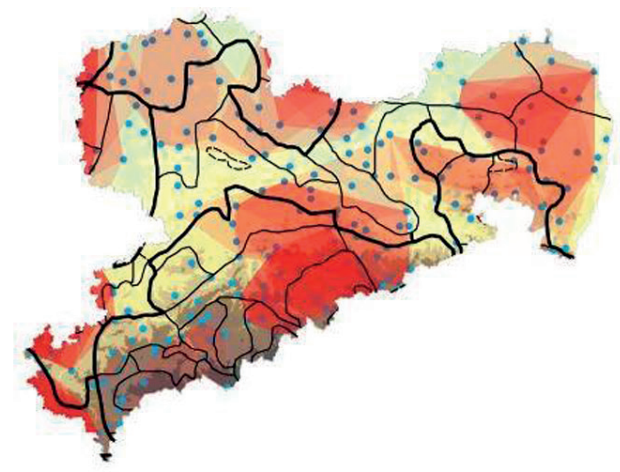

d)

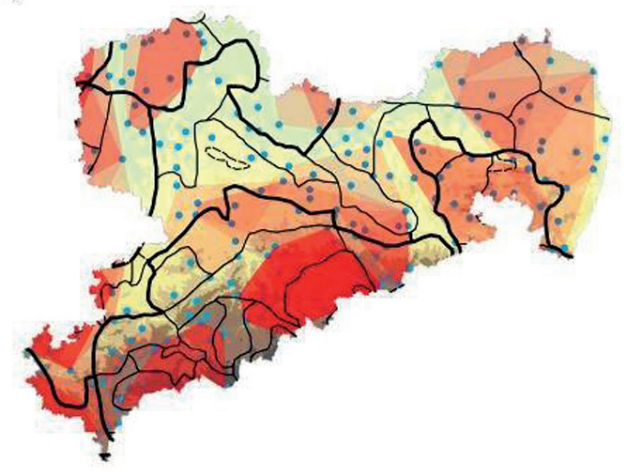

Legend

Precipitation Region

$\square$ Saxony

- Rain Gauge Regions after Mannsfeld ---- Precipitation District

- Climate District

Climate Region

Altitude (m) as $\square$ 0-60

$\square 60-160$

$\square 160-260$

$\square 360-460$

$460-560$

$560-660$

$660-760$

$760-860$

$860-1,250$
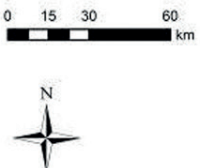

Fig. 2. Classification of seven precipitation regions per scenario and realisation. Each single precipitation region of a realisation is depicted in red for: a) WEREX-V SEL, b) WETTREG2010 A1B, c) WETTREG2010 A2, d) WETTREG2010 B1

a)

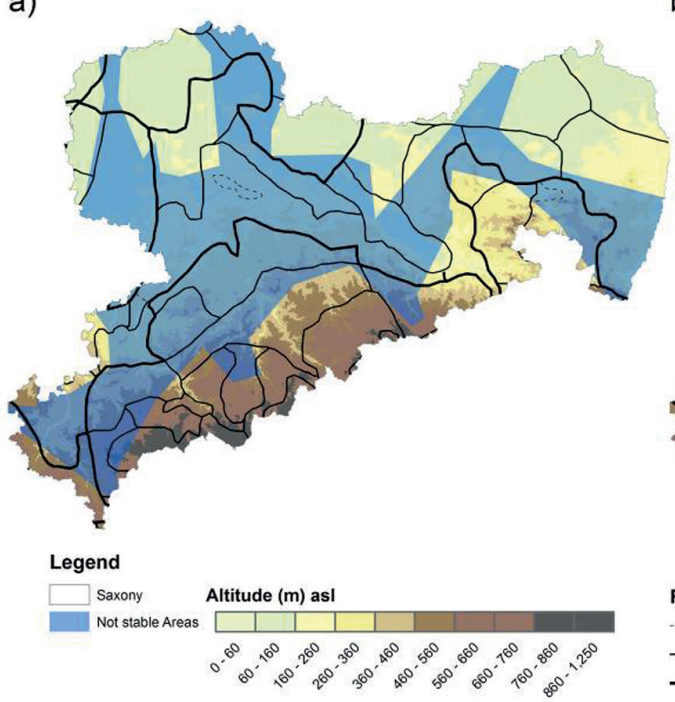

b)

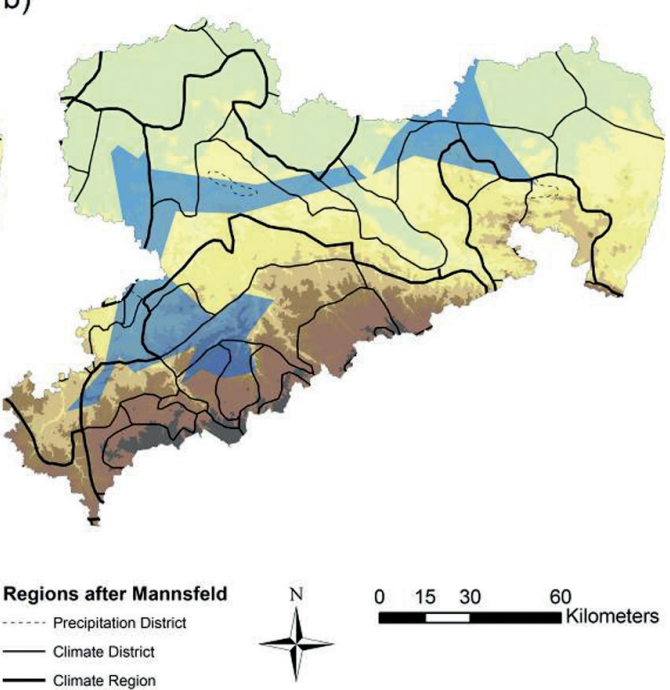

Fig. 3. Areas of instability in terms of a climate signal for the climatological precipitation conditions; a) WEREX-V SEL and for b) WETTREG2010 (i.e. all scenarios and realisations)

this reason two or more overlapping polygons of one realisation were not allowed - so that certain rain gauges were not recognised for the polygon construction. However, the comparison of different realisations shows that regions may overlap. In these cases the areas of similar precipitation can be called very stable and nearly invulnerable to climatological change - these regions at this spatial scale are more dominated by orographic features than by climatic and atmospheric conditions. However, this is only a qualitative interpretation. Further studies need to show how the stability of regions can be explained and quantified by dividing the influence into causes of climate change or simple orographic, geographic and land surface aspects.

The applied method does not allow a quantitative spatial interpretation due to the assumed constraints, like using only convex polygons and a limited number of rain gauges, especially at the borders of the study region. 
Also, the sharp constructed edges are not considered as fixed boundaries for the definition of possible precipitation regions, but only as a first approximation.

The most stable precipitation region can be found in the Ore Mountains (Erzgebirge in German), which are located along Saxony's southern border. This region is concentrated in the central and eastern parts of the mountain range. The observed stability is characterised by an independence of the considered data set to an almost constant extent in this region. Further stable regions can be found in the south-west and north-west of the study region. Regions of potential change in the climatological precipitation regime can be observed in the north-east, where Brandenburg borders Poland, and in the transition area from the northern lowlands to the south Ore Mountains. In this area a small precipitation district is classified by Mannsfeld and Syrbe (2008). Additionally, an area within a large climate region, after Mannsfeld and Syrbe (2008), in the south-west of the Ore Mountains, where two precipitation stations are located, is not included in any designated precipitation region by any model or any realisation.

The intersection of all precipitation regions lead to the areas depicted in Fig. 3, where areas of precipitation instability are shown. The larger areas of WEREX-V SEL may in principle not obscure the fact that just 10 realisations were recognised, instead of 30 WETTREG2010 realisations. Nevertheless, the core regions are similar and most likely can be found in the transition zone - from low to mountainous regions. However, the method does not suggest any further information what changes should be expected; it only indicates the potential for climatic change.

\subsection{Data verification and realisation choice by means of a Taylor diagram}

The validation of the considered raster data was carried out with the use of a Taylor diagram (Taylor 2001). This diagram generalises the classified regions by summarising their climatological properties spatially. The diagram illustrates the similarity between two patterns quantified by standard deviation, correlation and centred root-meansquare difference. The closer a point lies to the reference (i.e. at one on the abscissa) the higher the similarities between the simulated pattern and the reference state are (i.e. observed pattern).

All realisations of the deployed models (i.e. WEREX-V SEL, WETTREG2010 A1B, WETTREG2010 A2, WETTREG2010 B1) are compared to the observed state of the validation period. For this reason, the following configurations were considered for the analysis: the period definitions are shown in table 1; the validation period spans over the observed period of the DWD data to validate the deployed approach of pattern detection and the climate models; the reference period for validation results from a shortening of the time series due to the applied low pass filter - this period was also chosen because of the most similar gauge network configuration over a 40 -year period. It is known that this obvious short time period is not employed for the analysis of significant climate trends, but to verify the patterns of the considered models. For validation it was assumed that the projected data sets should form a similar pattern to the one the classification approach detects for the observed data. Hence, for validation no anomalies were used.

The validation of the data sets was elaborated as a comparison of similar complex climatic regions. Therefore, the sums of the three considered elements are calculated over a 40-year period for all pixels within the domain and validation period mentioned in table 1 . The obtained sums are subsequently classified into four classes by the method described in Section 3.2. The more classes were chosen in the validation, the larger the variance of the resulting classes became, or, in other words, the less significant the

Table 1. Data set configurations for different analyses of hydrometeorological spatial properties

\begin{tabular}{|c|c|c|}
\hline Analysis run & Validation & Projection \\
\hline Reference period & 1968 to 2007 & 1971 to 1980 \\
\hline Sub periods & - & 2021 to 2030 \\
& & 2031 to 2040 \\
& & 2041 to 2050 \\
& & 2051 to 2060 \\
& & 2061 to 2070 \\
& & 2071 to 2080 \\
& & 2080 to 2090 \\
\hline
\end{tabular}

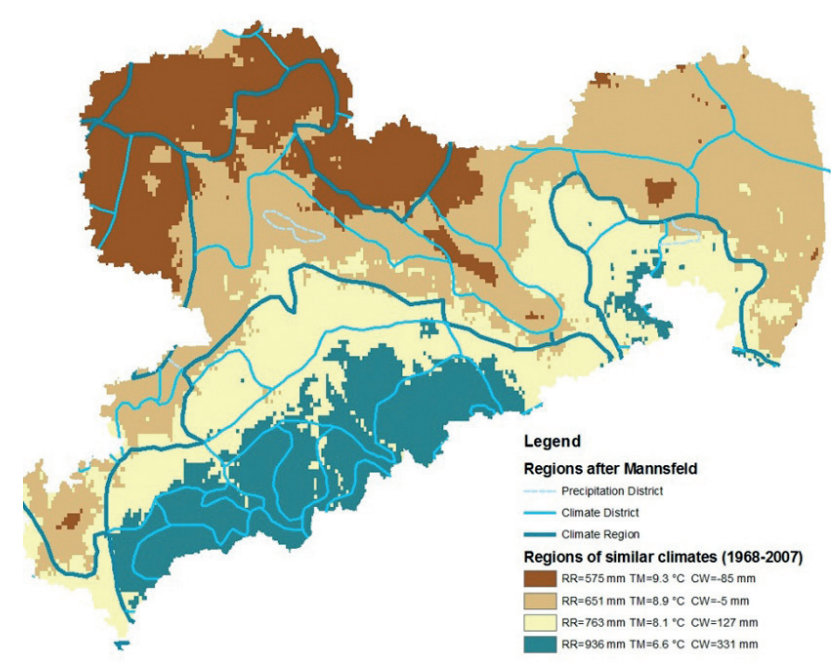

Fig. 4. Classified regions of similar climates for observed data in the period 1968 to 2007 
generalising character of the classification became. This is why four classes were deployed, as they are considered to be representative of the main orographic features in the study region. The observed patterns (i.e. regions of similar climates) are provided in fig. 4. They show good agreement with the climate regions introduced by Mannsfeld and Syrbe (2008).

The results of the pattern validation approach for all data sets are depicted in a comparison in fig. 5. The comparison takes into account the observed measurements of the validation period. This data is defined as reference in terms of the Taylor diagram (cp. fig. 5).

The summation of the considered elements allows a general analysis of complex climatological regions. It was expected that single classifications of precipitation and temperature would lead to similar regions to the observed state, and the climatic water balance, as a more complex derivative, should perform worse in the context of spatial similarity.

It can be clearly seen in fig. 5 that complex verification leads independently of the data set to good agreement between the modeled and observed climate regions. No realisation of all data sets performed worse than 0.85 in terms of correlation. Also, the differences of deviation are
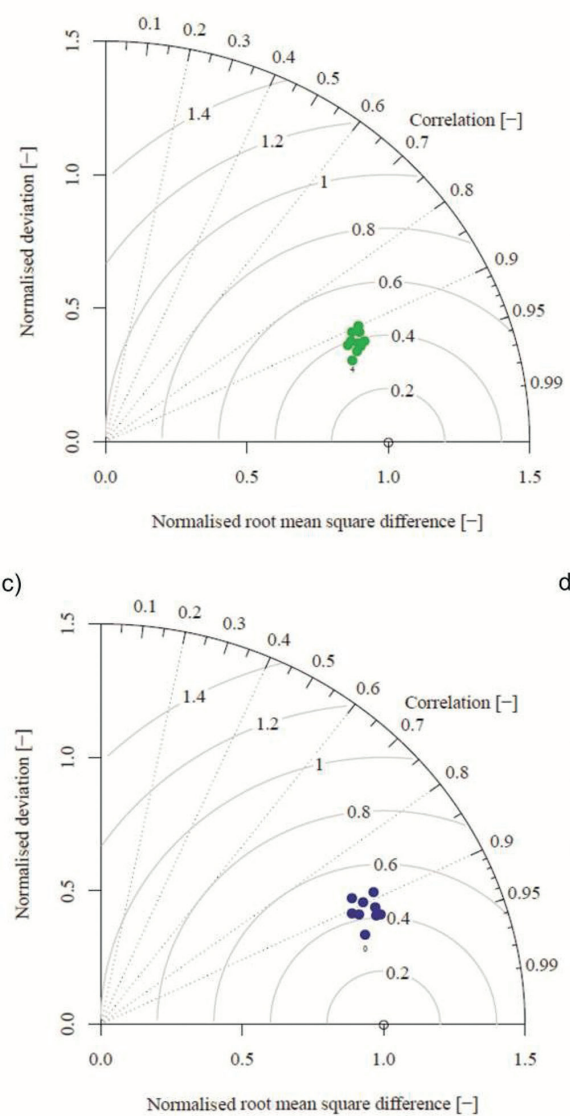

negligibly small. For further analysis, realisations were chosen which lay closest to the reference. The respective realisations are labelled in fig. 5.

\subsection{Potential areas of changing climatic conditions}

The detection of potential areas of changing climatic conditions was deployed for the defined projection period, as mentioned in Table 1. Instead of climate standard normal, only 10-year long periods were applied because in this manner more independent deviations and trends can be used for classification. The application of an 11-year low-pass filter decreases the fluctuation of the gridded time series. Furthermore, the subtraction of the reference period leads to time series of deviation and trend, in contrast to the observed mean values. RR, TM and CW were combined for the identification of areas of changing climatic conditions as a component of potential regional vulnerability. Hence, no climate regions were obtained by means of classification of these time series, but regions of similar changes in their complex climatological behavior, integrally over the considered meteorological elements, were. These changes only become significant for long (i.e. climatological) time series (Matulla et al. 2003).

b)

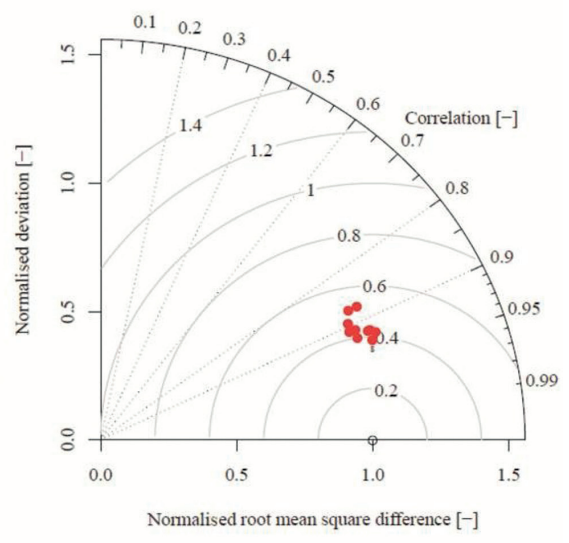

d)

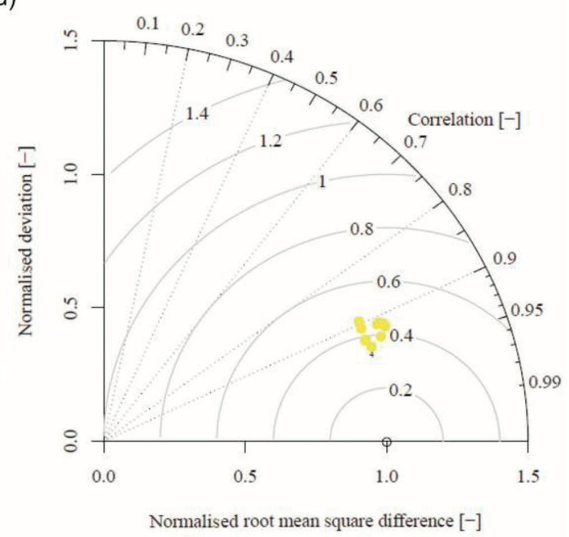

Fig. 5. Taylor diagram of complex climate regions defined by RR, TM and CW. The elements were classified into 4 regions within an extended domain around the Free State of Saxony for the period 1968-2007; the chosen realisation is labelled with its number; a) WEREX-V SEL, b) WETTREG2010 A1B, c) WETTREG2010 A2, d)WETTREG2010 B1 
The spatial results of this analysis are marked by a small heterogeneity of TM and the larger variability of $\mathrm{RR}$ and $\mathrm{CW}$.

The results for the chosen realisations are depicted in fig. 6. The regions of changing climate conditions are not given in absolute numbers, but are dimensionless due to normalisation. Therefore, these figures do not suggest a quantitative trend and the manifestation of changes only becomes noticeable in a comparison of different realisations.

The results of the classifications of similar climatic changes reveal a large range of possible future scenarios. This range might be explained by the applied data sets, which on the one hand possess an uncertainty related to the climate models, and on the other hand assume different climate scenarios, which are seen as the most dominant component in uncertainty. Wilby et al. (2009) underlined that emission scenario uncertainty contributes proportionately large uncertainty when contrasted with climate and impact model uncertainty. Hence, only a comparison shows the expected strength of future changes in Saxony.

On average, all regions will have to cope with changes in TM, RR and CW. The results do not support a dependency of similar changing climates due to orographic aspects, although certain spatial structures are recognisable,

a)

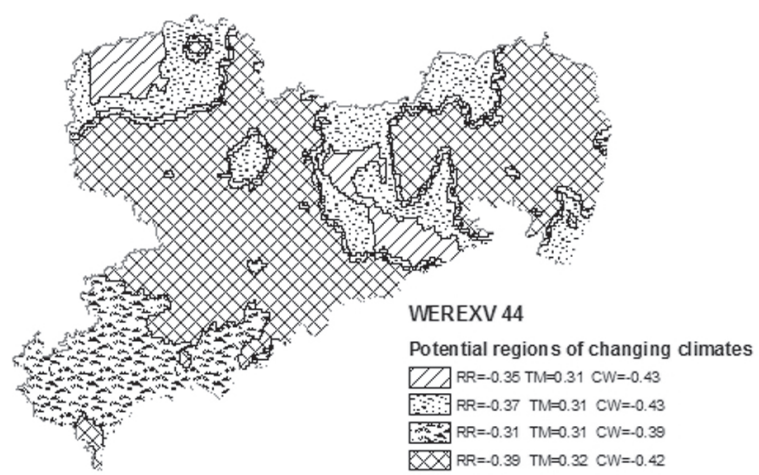

c)

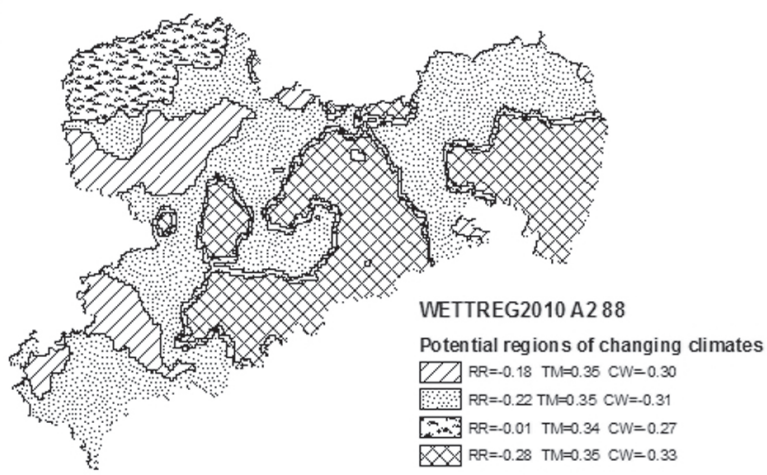

as shown in fig. 6. The designated regions are considered more likely to change with the changing occurrence of weather patterns; the deployed statistical climate models are primarily forced by such changes. This is why TM almost homogenously changes in the considered domain. Furthermore, it is assumed that these small spatial differences of changes in temperature are less dominant in classification than the large spatial and temporal variability of RR.

Despite the heterogeneity of the designated regions, spatial similarities can be observed. Thus, similar spatial structures can be found in the east of Saxony and in both western and eastern parts of the Ore Mountains. The selected WEREX-V 44 and WETTREG2010A1B 00 realisations are similar in their general properties. TM changes are almost equal for the classified areas. WETTREG2010A1B 88 seems a bit wetter and possesses a slightly lighter gradient of expected increase in CW. The largest negative changes in CW are expected for the WEREX-V 44 and WETTREG2010 A1B 00, while the WETTREG2010 A2 88 realisation possesses the smallest changes regarding $\mathrm{CW}$, and this is also small in terms of precipitation. The increase in precipitation is comparable to WETTREG2010 B1 44, whereas the negative changes in CW are stronger.

The revealed regions do not only change within the boundaries of the observed complex climate regions, but also with respect to future changes in a more com-

b)

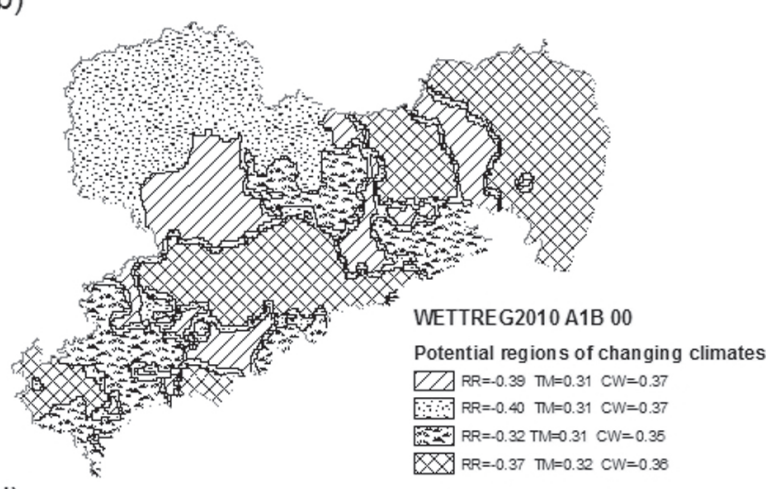

d)

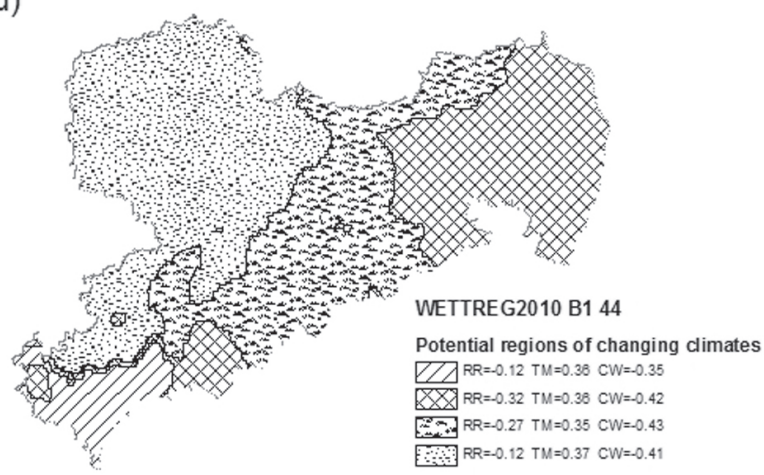

Fig. 6. Potential areas of climatic change for the chosen realisations; a) WEREX V EH5_L2_CLM_A1B 33, b) WETTREG2010 A1B 00, c) WETTREG2010 A2 88, d) WETTREG2010 B1 44. RR = change signal of precipitation; TM = change signal of temperature; $\mathrm{CW}=$ change signal of climatic water balance 
plex manner over the observed complex climate regions. The classification of complex trends reveals less common results than the presented precipitation regions. Similar trends not only differ at a regional but also at a meso-scale. Uncertainties due to interpolation are not neglected, but it is assumed that they occur in all data sets with the same level of error. This is why they do not influence the interpreted results immediately.

Despite the heterogeneity of the designated areas, major similarities in their spatial extent can be stated. Similar areas in the eastern part of Saxony, as well as in the western and eastern Ore Mountains, can be found. Due to the fact that the realizations depicted in fig. $6 \mathrm{a}$ and $6 \mathrm{~b}$ underlie the same scenario (i.e. A1B), they are directly comparable. The climatic changes of the realization in fig. 6d mainly follow the orographic structure with a weaker signal of change in RR in the north and west of Saxony and a more obvious decrease in RR in the Ore Mountains by an almost equivalent increase in TM. The heterogeneity of these potential areas of climatic changes, which can clearly be seen in Fig. 6c, can be explained: firstly by the complex element-spanning character of this analysis and the associated spatial variability of the anomalies; and secondly by the wide range of the realizations emerging from the respective scenarios.

\section{Conclusions}

Climate impact research is an important interface between practice and science. Impact questions concerning of the observed climate change are closely linked to future regional climate developments. In this context the detection of regions of changing climate behavior is becoming more and more important, as they indicate areas of increasing climate uncertainty, which should be investigated and for which special measures for adaptation in respective fields should be taken. Therefore, two aspects of potential climatological change have been investigated for Saxony until 2100.

In the first step, projected rain gauge-based data were applied. The analysis of this precipitation data revealed similar areas of stable and unstable conditions in terms of long-term precipitation behaviour for the statistical climate models WEREX-V and WETTREG2010. One important finding in this study is that most stable areas are located in mountain ranges like the Ore Mountains, while the transition zones from lowlands to mountains can be characterised as regions of instability in terms of longterm precipitation behaviour.

In the second part of this work, the projected time series of precipitation, temperature and climatic water balance were interpolated by the regionalisation service RaKliDA in $1 \mathrm{~km}$ resolution. With the use of a Taylor diagram, the closest four realisations of WEREX-V and WETTREG2010 were identified in terms of complex climate regions for the period 1968-2007. Hence, the derived complex climate regions were in good agreement with those derived from observed data. The four realisations were applied for an integrated spatial anomaly classification of precipitation, temperature and climatic water balance.

The classification results in heterogeneous patterns of projected spatial changes. The results are characterised by a large amount of spatial difference. Hence, an important outcome of the present analysis is that climate anomalies in space largely differ from the observed manifested complex climate regions.

The complex derived regions of climate anomalies show certain characteristics. Precipitation and climatic water balance anomalies, especially, possess a high amount of spatial variability, and, as such, potential vulnerability while the temperature anomalies are spatially very similarly distributed when different realisations and scenarios are compared. Therefore, it is concluded that spatial precipitation distribution is considered as the main reason for the derived patterns.

The wide range of results, which emerged from the emissions scenarios and subsequently the realisations, increases the difficulty of comparing the derived areas. The spatial classification of these anomalies revealed areas which are less dominated by orographic structures. Nevertheless, similarities were found which indicate reasonable future changes in precipitation, temperature and climatic water balance in certain areas of Saxony.

Acknowledgments. This work was financially supported by the Landesamt für Umwelt, Landwirtschaft und Geologie (LfULG) and the German academic exchange service (DAAD). Furthermore, the support by the German Weather Service (DWD) and the Czech Hydrological Meteorological Institute (CHMI) is gratefully acknowledged for providing the observed data.

\section{Bibliography}

Ashcroft L., Karoly D.J., Gergis J., 2013, Southeastern Australian climate variability 1860-2009: A multivariate analysis, International Journal of Climatology, 34 (6), 1928-1944, DOI: $10.1002 /$ joc. 3812

Berggren K., Olofsson M., Viklander M., Svensson G., Gustafsson A.-M., 2012, Hydraulic impacts on urban drainage systems due to changes in rainfall caused by climatic change, 
Journal of Hydrologic Engineering, 17 (1), 92-98, DOI: 10.1061/(ASCE)HE.1943-5584.0000406

Daniels E.E., Lenderink G., Hutjes R.W.A., Holtslag A.A.M., 2013, Spatial precipitation patterns and trends in the Netherlands during 1951-2009, International Journal of Climatology, 34 (6), 1773-1784, DOI: 10.1002/joc.3800

Drogue G., Wagner C., Mahr N., Hoffmann L., Pfister L., 2006, Topography and recent winter rainfall regime change in temperate Western European areas: a case study in the RhineMeuse basin, International Journal of Climatology, 26 (6), 785-796, DOI: 10.1002/joc.1285

Franke J., Häntzschel J., Goldberg V., Bernhofer C., 2008, Application of a trigonometric approach to the regionalization of precipitation for a complex small-scale terrain in a GIS environment, Meteorological Applications, 15 (4), 483-490, DOI: $10.1002 /$ met.91

Freitas C.R. de, Helbig M., Matzarakis A., 2013, Hydroclimatic assessment of water resources of low Pacific islands: evaluating sensitivity to climatic change and variability, International Journal of Climatology, 34 (3), 881-892, DOI: $10.1002 /$ joc. 3731

IPCC, 2008, Climate change 2007: Synthesis Report, Intergovernmental Panel on Climate Change, Pachauri R.K., Meyer L.A. (eds.), Geneva, Switzerland, 104 pp.

IPCC, 2014, Climate Change 2014: Synthesis Report, Contribution of Working Groups I, II and III to the Fifth Assessment Report of the Intergovernmental Panel on Climate Change, Pachauri R.K., Meyer L.A. (eds.), Geneva, Switzerland, 151 pp.

Kreienkamp F., SpekatA., Enke W., 2010, Ergebnisse eines regionalen Szenarienlaufs für Deutschland mit dem statistischen Modell WETTREG2010, Bericht an Das Umweltbundesamt, Potsdam

Mannsfeld K., Syrbe R.-U., 2008, Naturräume in Sachsen, Forschungen zur Deutschen Landeskunde, Bd. 257, Leipzig: Deutsche Akademie für Landeskunde

Matulla C., Penlap E.K., Haas P., Formayer H., 2003, Comparative analysis of spatial and seasonal variability: Austrian precipitation during the 20th century, International Journal of Climatology, 23 (13), 1577-1588, DOI: 10.1002/joc.960

Nguyen D.-Q., Renwick J., McGregor J., 2013, Variations of surface temperature and rainfall in Vietnam from 1971 to 2010, International Journal of Climatology, 34 (1), 249-264, DOI: $10.1002 /$ joc. 3684

Osborn T.J., Hulme M., Jones P.D., Basnett T.A., 2000, Observed trends in the daily intensity of United Kingdom precipitation, International Journal of Climatology, 20 (4), 347-364, DOI: 10.1002/(SICI)1097-0088(20000330)20:4<347::AIDJOC475>3.0.CO;2-C

Patz J.A., Campbell-Lendrum D., Holloway T., Foley J.A., 2005, Impact of regional climate change on human health, Nature, 438 (7066), 310-317, DOI: 10.1038/nature04188
Reiter A., Weidinger R., Mauser W., 2011, Recent climate change at the Upper Danube - A temporal and spatial analysis of temperature and precipitation time series, Climatic Change, 111 (3-4), 665-696, DOI: 10.1007/s10584-011-0173-y

Renner M., Brust K., Schwärzel K., Volk M., Bernhofer C., 2013, Separating the effects of changes in land cover and climate: a hydro-meteorological analysis of the past $60 \mathrm{yr}$ in Saxony, Germany, Hydrology and Earth System Sciences Discussions, 10 (7), 8537-8580, DOI: 10.5194/hessd-10-8537-2013

Romano E., Preziosi E., 2013, Precipitation pattern analysis in the Tiber River basin (central Italy) using standardized indices, International Journal of Climatology, 33 (7), 1781-1792, DOI: $10.1002 /$ joc.3549

SMUL, 2008, Staatsministerium für Umwelt und Landwirtschaft, Sachsen im Klimawandel eine Analyse. Dresden: Zentraler Broschürenversand der Sächsischen Staatsregierung

Taylor K.E., 2001, Summarizing multiple aspects of model performance in a single diagram, Journal of Geophysical Research: Atmospheres, 106 (D7), 7183-7192, DOI: 10.1029/2000JD900719

Ward J.H., 1963, Hierarchical grouping to optimize an objective function, Journal of the American Statistical Association, 58 (301), 236-244, DOI: 10.1080/01621459.1963.10500845

WEREX-V, 2011, WEREX V - Bereitstellung Eines Ensembles Regionaler Klimaprojektionen, Dresden: Sächsisches Landesamt für Umwelt, Landwirtschaft und Geologie

Wilby R.L., Keenan R., 2012, Adapting to flood risk under climate change, Progress in Physical Geography, 36 (3), 348378, DOI: $10.1177 / 0309133312438908$

Wilby R.L., Troni J., Biot Y., Tedd L., Hewitson B.C., Smith D.M., Sutton R.T., 2009, A review of climate risk information for adaptation and development planning, International Journal of Climatology, 29 (9), 1193-1215, DOI: 10.1002/ joc. 1839

Wójcik R., Pilarski M,, Miętus M., 2014, Statistical downscaling of probability density function of daily precipitation on the Polish coast, Meteorology Hydrology and Water Management, 2 (1), 27-36

Zhang Q., Li J., Singh V.P., Xu C.-Y., 2013, Copula-based spatiotemporal patterns of precipitation extremes in China, International Journal of Climatology, 33 (5), 1140-1152, DOI: 10.1002/joc.3499

Zhao J., Han Y.-B., Li Z.-A., 2004, The effect of solar activity on the annual precipitation in the Beijing area, Chinese Journal of Astronomy and Astrophysics, 4 (2), 189-197, DOI: $0.1088 / 1009-9271 / 4 / 2 / 189$ 